\title{
El divorcio por mutuo consentimiento de matrimonio sin hijos ni dependientes
}

\author{
Divorce by mutual consent of marriage without children or dependents
}

Divórcio por consentimento mútuo de casamento sem filhos ou dependentes

\section{Nelson Alejandro Enríquez Caicedo \\ alejandroecuador1@gmail.com \\ https://orcid.org/0000-0001-6230-2627}

\author{
Edison Manuel Pozo Calderón \\ emanuelpozoc@hotmail.com \\ https://orcid.org/0000-0002-0909-693X
}

Universidad Regional Autónoma de los Andes “UNIANDES”. Ambato, Ecuador

Artículo recibido en abril 2021 | Arbitraje en mayo 2021 | Aceptación en junio 2021 | Publicación en julio 2021

RESUMEN

\section{ABSTRACT}

\section{RESUMO}

La investigación tuvo por objetivo elaborar un anteproyecto de Ley Reformatoria al Código Civil y Ley de Arbitraje y Mediación, que garantice el acceso a mediación en caso de divorcio por mutuo consentimiento sin hijos ni dependientes. Metodológicamente fue de tipo descriptivo propositivo, bajo un enfoque mixto, y un diseño documental de campo, con los métodos deductivo-inductivo y analíticosintético. La técnica e instrumento utilizado fue la encuesta (cuestionario). La población y muestra estuvo conformado por 17946 profesionales inscritos en el Foro de abogados de la provincia de Pichincha, y de muestra 99. Como resultado se obtuvo que es fundamental una Ley Reformatoria a la Ley de Arbitraje y Mediación con el fin de garantizar en los divorcios por mutuo consentimiento, en los casos en que los cónyuges no tengan hijos menores de edad o bajo su dependencia, para garantizar los principios de celeridad, economía procesal y gratuidad de la justicia.

Palabras clave: Divorcio; código civil; ley arbitraje y mediación; mutuo consentimiento

The objective of the investigation was to prepare a draft of the Reform Law to the Civil Code and the Law of Arbitration and Mediation, which guarantees access to mediation in the event of divorce by mutual consent without children or dependents. The methodology was of a descriptive propositional type, under a mixed approach, and a documentary field design, with deductive-inductive methods; analyticalsynthetic, others. The technique and instrument used was the survey (questionnaire). The population and sample were made up of 17,946 professionals registered in the Pichincha Province Lawyers Forum, and 99 sampled. As a result, it was obtained that a reform of the Reform Law to the Arbitration and Mediation Law is fundamental. To guarantee in divorces by mutual consent, in cases in which the spouses do not have minor children or under their dependence to guarantee the principles of speed, procedural economy and free justice.

Key words: Crimes; corruption; Bolivian legislation; law 004, transgression

O objetivo da investigação é preparar um projeto de Lei de Reforma do Código Civil e da Lei de Arbitragem e Mediação, que garante o acesso à mediação em caso de divórcio por mútuo consentimento sem filhos ou dependentes. A metodologia foi do tipo proposicional descritiva, sob abordagem mista, e de campo documental, com métodos dedutivo-indutivos; analítico-sintético, outros. A técnica e instrumento utilizados foi o inquérito (questionário). A população e a amostra constituíram-se de 17.946 profissionais inscritos no Fórum de Advogados da Província de Pichincha e da amostra de 99. Como resultado, obtevese que uma reforma da Lei de Reforma da Lei de Arbitragem e Mediação é fundamental. Garantir nos divórcios por mútuo consentimento, nos casos em que os cônjuges não tenham filhos menores ou sob a sua dependência, para garantir os princípios da celeridade, economia processual e liberdade de justiça.

Palavras-chave: Divórcio; Código Civil; arbitragem e lei de mediação; consentimento mútuo 
En Ecuador los procesos para disolver el vínculo matrimonial se limitan a dos alternativas dependiendo el caso, el primero tiene que ver con el ámbito jurisdiccional cuando se trata de un divorcio controvertido, y el segundo tiene que ver con el ámbito notarial. Es así, que cuando en la institución jurídica del matrimonio se presentan conflictos irreconciliables entre los cónyuges y deciden terminar con su matrimonio, se inician procesos jurídicos con esa finalidad y para ese efecto la ley determina que cuando se trate de procesos de divorcio controvertidos, esto es, cuando se trate de matrimonios en los que existan hijos menores de edad. Y cuando se trata de los cónyuges que deciden divorciarse en matrimonios donde no existan hijos menores de edad, la ley determina que el divorcio se debe realizar por la vía notarial.

Los dos procedimientos de terminación del vínculo matrimonial antes mencionados, obedecen a una estructura rígida procedimental, pero no brinda una efectividad en los resultados, con respecto a los principios jurídicos de celeridad y economía procesal. En ese sentido la ley faculta que cuando se trate de procedimientos de divorcios controvertidos en los que para declarar disuelto el vínculo matrimonial se necesite una sentencia judicial, el procedimiento obligue a realizar la prueba necesaria a través de la presentación de testigos, testimonios o evidencias que de una manera objetiva determinen que se ha incurrido en una de las causales que determina el Código Civil. Para la terminación del matrimonio efectivamente se necesita de este procedimiento jurisdiccional en forma rigurosa.

Sin embargo, de lo manifestado en líneas anteriores, en este procedimiento jurisdiccional controvertido previo a sentenciar el divorcio, el juez debe resolver los asuntos relacionados con los menores, esto es, con cuál de los padres van a permanecer, qué pensión alimenticia se va a suministrar a favor de ellos, por parte de aquel padre que no vaya a convivir con los menores, $y$, sobre los asuntos relacionados con los bienes adquiridos dentro de la sociedad conyugal, esto es, todo lo que tienen que ver con la disolución de la sociedad conyugal y con la liquidación de la sociedad conyugal.

De tal forma que para disolver el matrimonio controvertido en vía jurisdiccional se requiere de un tiempo preestablecido para cada etapa de las mencionadas, lo que extiende el proceso para obtener un resultado ágil, que es lo que la ciudadanía espera de la justicia en ese fin.

Por otro lado, en el procedimiento notarial, que es más limitado, pues como requisito principal no deben existir hijos menores de edad ni bienes obtenidos dentro de la sociedad conyugal.

Es así como la investigación tuvo el propósito que la disolución del vínculo matrimonial por mutuo consentimiento se realice por vía de jurisdicción voluntaria como lo es "la mediación", siendo así que en este planteamiento se podrían resolver todos los asuntos previos y en un solo acto jurídico como es "el acta de mediación", en particular lo relacionado con los bienes, la disolución de la sociedad conyugal y la liquidación de bienes de la sociedad conyugal. 
Además, que en la misma acta se puede resolver lo relacionado con la tenencia de los menores y la alimentación. De esta manera, por decisión de voluntad mutua se procedería a declarar disuelto el vínculo matrimonial existente entre los cónyuges y a ordenar mediante la misma acta de mediación que el divorcio sea inscrito en el Registro Civil correspondiente.

Sin embargo, en la actualidad la carga procesal en los juzgados es abundante lo que impide que trámites, los cuales por su naturaleza (el mutuo consentimiento) sean ágiles, gocen de la celeridad que la ley lo prevé y que la ciudadanía no anhela, más aún cuando en lo medular se necesita la evacuación de las pruebas lo que incrementa la suma de los tiempos procesales.

Los procedimientos notariales que si han coadyuvado a alivianar la carga judicial tampoco brindan un resultado eficiente, pues limita sus resultados a la resolución de asuntos previos como los son los bienes y los menores en caso de que los haya dificulta una pronta obtención del resultado deseado.

En cuanto a los costos que deben pagar las personas por el acceso a los servicios de justicia para conseguir el divorcio dificulta y restringe su utilización, ya que, conceptualmente estos servicios al tratarse del acceso a la justicia no deberían tener ningún costo sin que esto ocurra en la realidad.

De este modo, que los procesos de divorcio sean tratados en vía de mediación no solo contribuiría a un alivio de la carga procesal de los juzgados, sino que además acumularía en un solo proceso como lo es el acta de mediación, todos los asuntos previos para la culminación de la disolución del vínculo matrimonial, poniendo así, fin a un conflicto que en muchos casos pueden llegar a tomar varios meses de tratamiento judicial y en los Centros de Mediación de la Función Judicial no existen cobros de tasas en materia de familia, en tal virtud se estaría cumpliendo con los postulados constitucionales de la gratuidad y el acceso a la justicia.

Por lo tanto, la investigación tuvo por objetivo principal elaborar un anteproyecto de Ley Reformatoria al Código Civil y Ley de Arbitraje y Mediación, que garantice el acceso a mediación en caso de divorcio por mutuo consentimiento sin hijos ni dependientes.

Es necesario tratar sobre los vacíos legales respecto a los divorcios por mutuo consentimiento, únicamente en los casos en que los cónyuges no tengan hijos menores de edad o bajo su dependencia para garantizar el acceso a la mediación, los principios de celeridad, economía procesal y gratuidad de la justicia.

\section{Marco teórico}

\section{Divorcio}

Planiol (1981) indica que la palabra divorcio proviene del latín divertere. Dicho término entraña que cada cual se va por su lado, divergen sus caminos. Quienes tenían vida en común, cambian su ruta. Originalmente iban juntos. 
El divorcio es la forma legal de extinguir un matrimonio válido en vida de los cónyuges por causas surgidas con posterioridad a la celebración del mismo y que permite a los divorciados contraer con posterioridad nuevo matrimonio válido. De acuerdo a su forma legal, el divorcio solo puede demandarse por las causas previamente establecidas en la ley, ante la autoridad competente y cumpliendo con todos los requisitos legales de procedimiento. (Diccionario Jurídico Mexicano, 1989).

\section{Divorcio en el Código Civil Ecuatoriano}

El divorcio en Ecuador tiene su propia reseña histórica ya que, la introducción de esta figura en el ordenamiento jurídico supuso un extraordinario alcance y fue un debatido acontecimiento, por diversos aspectos, desde la época misma en la que esta institución se introdujo en Ecuador, hasta las connotaciones morales y sociales que el tema implica. Es en 1895 que se estableció por primera vez el matrimonio civil y en 1902 se admitió el divorcio por adulterio de la mujer.

En la actualidad y con las últimas reformas del cuerpo normativo vigente en el Código Civil ecuatoriano (2005), en el artículo 106 la definición del mismo:

El divorcio disuelve el vínculo matrimonial y deja a los cónyuges en aptitud para contraer nuevo matrimonio, salvo las limitaciones establecidas en este Código. De igual manera, no podrá contraer matrimonio, dentro del año siguiente a la fecha en que se ejecutorió la sentencia, quien fue actor en el juicio de divorcio, si el fallo se produjo en rebeldía del cónyuge demandado. Estas prohibiciones no se extienden al caso en que el nuevo matrimonio se efectúa con el último cónyuge.

Es importante aclarar que el matrimonio dentro de la legislación se da por medio de un acto jurídico solemne que implica el consenso de dos voluntades entre personas de distinto sexo con obligaciones preestablecidas por la norma pertinente. El mismo se puede disolver por dos vías: la primera es el divorcio por mutuo consentimiento y la segunda es el divorcio por causales, las características y procedimientos de ambos se detallan a continuación.

\section{Divorcio por mutuo consentimiento}

El divorcio por mutuo consentimiento de ambos cónyuges, que está previsto en el artículo 107 del Código Civil ecuatoriano (2005).

El mutuo consentimiento consiste en que ambos cónyuges coinciden en poner fin al vínculo matrimonial, y es generalmente reconocido como causa de divorcio, aunque en algunos sistemas se exige, además de su concurrencia, el cese efectivo de la convivencia durante un cierto período de tiempo. 
El artículo 107 del Código Civil de Ecuador (2005) manifiesta:

Por mutuo consentimiento pueden los cónyuges divorciarse. Para este efecto, el consentimiento se expresará del siguiente modo; los cónyuges manifestaran por escrito, por sí o por intermedio de procuradores especiales, ante un Juez de lo Civil del domicilio de cualquiera de los cónyuges.

De este modo el divorcio consensual, es el que decide por mutuo consentimiento de ambos cónyuges y que es declarado por sentencia judicial.

Di Antonio (1998) manifiesta que:

...esta clase de divorcio, evita escándalos entre los cónyuges y la circunstancia de no establecer al culpable, pero no surte efecto sin aprobación judicial dictada en sentencia por el Juez de lo Civil competente, pues de lo contrario sería nulo. (s.n.).

En la mayoría de casos cuando se ha llegado al divorcio por mutuo consentimiento, se da por varios acuerdos previos entre las parejas, sin tener que llegar a ningún otro tipo de litigios por los hijos, ni por los bienes que fueron obtenidos dentro del matrimonio. En síntesis, el divorcio consensual en la legislación ecuatoriana puede caracterizarse como una institución en la que no se requiere expresión ni calificación de causas, que solamente procede en virtud de sentencia judicial.

\section{Arbitraje y Mediación}

Salcedo (2012) considera al arbitraje como un medio para la solución de conflictos intersubjetivos. También lo define como una institución de solución privada de un conflicto de intereses, un proceso privado.

Conjuntamente, Zurita (2001) lo indica que las partes recurren a árbitros (jueces privados) para un procedimiento adversario que guarda las formalidades dentro de un juicio, en donde finaliza con un dictamen que se denomina laudo arbitral (sentencia) de resolución obligatoria.

Mientras que, la mediación la define como la "acción de mediar, nexo de relación entre dos entidades". (Cazorla, 2000, p. 3).

Cazorla (2000) también indica que "es un procedimiento de solución de conflictos por el cual las partes, asistidas por un tercero neutral llamado mediador, procuran un acuerdo voluntario, que verse sobre materia transigible, de carácter extra judicial y definitivo, que ponga fin al conflicto" (p.3). 


\section{Divorcio por mutuo consentimiento ante Juez y Notario}

Según el Código Orgánico General de Procesos en el artículo 340 menciona lo siguiente: "divorcio o terminación de unión de hecho por mutuo consentimiento. El divorcio o la terminación de unión de hecho por mutuo consentimiento, siempre que haya hijos dependientes, se sustanciará ante la o el juzgador competente (...)".

Además en el artículo 358 del Código Orgánico General de Procesos (2015), se establece:

La o el juzgador convocará a los cónyuges o a los convivientes a audiencia a la cual comparecerán personalmente o a través de la o del procurador judicial y ratificarán su decisión de dar por terminado el vínculo matrimonial o la unión de hecho. Si en la audiencia, los cónyuges o los convivientes han acordado sobre la situación de las o los hijos menores de dieciocho años y de los bienes, la o el juzgador en el acto pronunciará sentencia declarando disuelto el vínculo matrimonial o la unión de hecho.

En caso de divorcio o terminación de la unión de hecho se dispondrá la inscripción de la sentencia conforme con la ley. De no haber acuerdo sobre la situación de las o los hijos menores de dieciocho años, el asunto se sustanciará ante la o el mismo juzgador en procedimiento sumario y resuelta esta controversia se declarará disuelto el vínculo matrimonial o la unión de hecho.

\section{Arbitraje en Ecuador}

Los antecedentes del arbitraje en Ecuador se remontan hasta épocas muy antiguas. La conciliación y el arbitraje aparecen regulados en el sistema jurídico (en el período preindependentista cuando la Gran Colombia, del que el Ecuador formaba parte, pertenecía al imperio español), en la Constitución Política de la Monarquía Española, promulgada en Cádiz el 19 de marzo de 1812, que en su Capítulo II, desarrolla "de la Administración de Justicia en lo Civil", y establece en el artículo 280: no se podrá privar a ningún español del derecho de terminar sus diferencias por medio de los jueces árbitros.

La citada Constitución de 1812 contempla el instituto arbitral, no como instrumento para evitar el proceso, sino como fórmula de arreglo de las controversias por una vía distinta de la jurisdiccional. En la conciliación ya se daban algunas garantías propias del proceso, como la audiencia bilateral de las partes, el informe o dictamen de dos asociados, la resoluciónprovidencia que tenía fuerza entre los interesados, y en que su caso daba por terminado el pleito en caso de haberse iniciado.

El Estado como parte procesal en un juicio arbitral no es un tema nuevo en Ecuador. La codificación del Código de Procedimiento Civil de febrero de 1953, incorporó una sección 
específica bajo el epígrafe "Juicio por Arbitraje" y previó que los representantes de las personas jurídicas de derecho público estaban autorizados para comprometer la controversia en árbitros, así como para nombrarlos (Highton y Álvarez, 2014).

Sin embargo, de que esta normativa se mantuvo en las codificaciones de 1960 y de 1978, la repercusión que alcanzó en la práctica fue mínima. El prestigio e independencia de que gozaba la justicia ordinaria determinaba que todas las controversias que involucraban a entidades de derecho público sean resueltas por los órganos de administración de la justicia común y que no haya habido necesidad de métodos alternos para asegurar esa independencia y acierto, al menos no en lo tocante a conflictos de inversionistas nacionales con el Estado ecuatoriano.

Adicionalmente, las normas del Código de Procedimiento Civil que regulaban el "Juicio por Arbitraje" eran excesivamente reglamentarias y desalentaban la opción que ofrecía el arbitraje: se exigía que el compromiso arbitral contenga el texto completo de la demanda y la contestación, es decir que la controversia haya surgido previamente; se establecía el derecho a apelar de la sentencia arbitral ante los jueces ordinarios con lo cual la eficacia de un juicio ágil como pretende ser el arbitral, quedaba enervada por la posible iniciación de un nuevo proceso ante los jueces de lo civil.

El gran impulso al sistema arbitral ecuatoriano como un método alternativo de solución de controversias, -incluidas las que comprometen al Estado-, lo dio la nueva (Ley de Arbitraje y Mediación, 1997), que reconoció de manera abierta y categórica que el Estado y demás entes de derecho público podían someter al juicio de árbitros las controversias originadas en una relación jurídico contractual.

La consagración de los métodos alternos de solución de conflictos que hizo la (Constitución Política, 1998), fue el impulso formal más importante al sistema de arbitraje ecuatoriano y a la composición de controversias entre el Estado y los particulares, bajo las reglas de la mediación y del arbitraje. Por primera vez, normas de la más alta jerarquía del ordenamiento reconocieron al arbitraje y a otros métodos alternos a la justicia ordinaria como sistemas eficaces para componer conflictos de carácter jurídico (artículo. 191 inciso 3).

\section{Mediación}

El origen histórico de la mediación, se estudia desde el origen mismo del hombre, la mediación tiene raíces históricas y culturales antiquísimas. Los orígenes de la mediación se remontan a principios de la civilización y son anteriores a la justicia pública y a la aparición de los jueces. Aparece como un producto de la evolución de la justicia por mano propia. (Manual de formación básica de mediadores, 2013). 
La mediación, tal como ahora se conoce, no es sino una adaptación actualizada de la que ya existía en otras culturas, en otras épocas. Según el Manual de formación básica de mediadores (2013), se dice:

Estados Unidos. Los primeros puritanos y los colonizadores holandeses utilizaron la mediación, el arbitraje y la conciliación para asegurar el cumplimiento de los principios morales y las tradiciones de su grupo, acudiendo al sistema legal como último recurso.

Francia. Los antecedentes de este país datan desde la figura de ombudsman, personaje que actuaba como tercero mediador entre los particulares y los distintos organismos estatales, esta institución data del año 1973 en que se dictó la ley instituyendo el Mediador de la Republica. El primer ámbito donde se comenzó a desarrollar la mediación es el Derecho de Trabajo.

Japón. La mediación tiene viejas raíces en sus costumbres y leyes. En sus pueblos se esperaba que un líder ayudara a resolver las disputas. En los tribunales japoneses, se dispuso legalmente la conciliación de desavenencias personales antes de la segunda guerra mundial.

Uruguay. El sistema uruguayo se asienta en dos pilares sobre los que se ha construido la conciliación, que son los jueces y los abogados, fundamentalmente los jueces de paz. Por otra parte, los abogados acostumbran llevar cabo las negociaciones para llegar a una conciliación.

Colombia. El Congreso Nacional de Colombia a través de la Ley 23 del año 1991, creo una serie de mecanismos, que actúan como alternativos a la justicia, tendientes a descongestionar la tarea de esta última. Los llamados centro de mediación (contemplados en la ley citada) está bajo el control del Ministerio de Justicia, este autoriza los centros de mediación.

\section{Derecho a la celeridad, economía procesal y gratuidad de la Justicia}

La Constitución de la República del Ecuador (2008), reconoce y garantiza:

Art. 66.- Se reconoce y garantizará a las personas: [...] 25.- El derecho a acceder a bienes y servicios públicos y privados de calidad, con eficiencia, eficacia y buen trato, así como a recibir información adecuada y veraz sobre su contenido y características. [...] (Asamblea Nacional Constituyente reunida en Montecristi, 2008, p. 22).

La Constitución de la República del Ecuador (2008) en su artículo 52 establece que elegirlos, así como a una información precisa y no engañosa sobre su contenido. [...] todos los ciudadanos tenemos derecho a disponer de bienes y servicios de óptima calidad, libertad para [...] (Asamblea Nacional Constituyente reunida en Montecristi, 2008, p. 17). 
El artículo 53 de la Constitución de la República del Ecuador (2008), determina que las empresas, instituciones y más organismos que prestan servicios públicos deben incorporar sistemas de medición de satisfacción de los consumidores, y poner en la práctica sistemas de atención y reparación.

La Constitución de la República del Ecuador (2008) reconoce y garantiza en el artículo. 227:

La administración pública constituye un servicio a la colectividad que se rige por los principios de eficacia, eficiencia, calidad, jerarquía, desconcentración, descentralización, coordinación, participación, planificación, transparencia y evaluación. (Asamblea Nacional Constituyente reunida en Montecristi, 2008, p. 74).

De esta forma, la administración pública e instituciones públicas, deben brindar y prestar un servicio de calidad, esto es con eficacia, eficiencia, calidad, jerarquía, desconcentración, descentralización, coordinación, participación, planificación, transparencia y evaluación.

La Constitución de la República del Ecuador (2008), reconoce y garantiza:

Artículo. 314.- El Estado será responsable de la provisión de los servicios públicos de agua potable y de riego, saneamiento, energía eléctrica, telecomunicaciones, vialidad, infraestructuras portuarias y aeroportuarias, y los demás que determine la ley.

El Estado garantizará que los servicios públicos y su provisión respondan a los principios de obligatoriedad, generalidad, uniformidad, eficiencia, responsabilidad, universalidad, accesibilidad, regularidad, continuidad y calidad. El Estado dispondrá que los precios y tarifas de los servicios públicos sean equitativos, y establecerá su control y regulación. (Asamblea Nacional Constituyente reunida en Montecristi, 2008, p. 96).

\section{Celeridad}

La celeridad obliga a las administraciones públicas a cumplir sus objetivos y fines de satisfacción de los intereses públicos, a través de los diversos mecanismos, de la forma más expedita, rápida y acertada posible para evitar retardos indebidos. Este principio le impone exigencias, responsabilidades y deberes permanentes a todos los entes públicos que no pueden declinar de forma transitoria o singular. 
Sánchez (2004) señala que:

La celeridad procesal aparece como un principio dirigido a la actividad procesal, sea del órgano jurisdiccional como del órgano fiscal, a fin de que las diligencias judiciales se realicen con la prontitud debida, dejando de lado cualquier posibilidad que implique demora en el desarrollo y continuidad del procedimiento. Desde la perspectiva del justiciable o de las partes en general, puede invocarse el mismo principio aun cuando es posible su exigencia a título de derecho, del derecho a un proceso sin dilaciones indebidas. (pp. 286-287).

La celeridad procesal resulta indispensable para la consecución del ideal de la tutela jurisdiccional efectiva.

Así mismo, el artículo 20 del Código Orgánico de la Función Judicial (2009), abarca los principios de la celeridad, el cual indica que:

La administración de justicia será rápida y oportuna, tanto en la tramitación y resolución de la causa, como en la ejecución de lo decidido. Por lo tanto, en todas las materias, una vez iniciado un proceso, las juezas y jueces están obligados a proseguir el trámite dentro de los términos legales, sin esperar petición de parte, salvo los casos en que la ley disponga lo contrario. El retardo injustificado en la administración de justicia, imputable a las juezas, jueces y demás servidoras y servidores de la función judicial y auxiliar de la justicia, será sancionado de conformidad con la ley. (p. 9).

La celeridad procesal no es un principio abstracto; muy por el contrario, es el alma del servicio de justicia. Está claro que la existencia del debido proceso se debe necesariamente a la existencia de una justicia que no puede y no debe prolongar innecesariamente el litigio; ya que la sociedad debe recomponer su paz a través del proceso en el más breve plazo; y es de su interés que el conflicto de intereses o la incertidumbre jurídica se dilucide prontamente. Esta situación, ya se encuentra reconocida constitucionalmente en el derecho comparado y en el proyecto constitucional.

\section{Economía procesal}

El principio de economía procesal trata de que dentro del proceso se produzca abreviaciones y simplificaciones, con la finalidad de que se evite su irrazonable prolongación haga inoperante la tutela de los derechos e intereses comprendidos en este principio.

Couture (1958), manifiesta:

a) simplificación en las formas de debate: los procesos de menor importancia económica se debaten en método oral, reducidas las exposiciones a simples actas de resumen; b) limitación de las pruebas: las pruebas onerosas (como, por ejemplo, la de peritos) se simplifican reduciéndose el nombramiento a un solo experto; c) reducción de los recursos: el número de instancias es normalmente 
menor en los asuntos de escaso monto y, en algunos casos, cuando la cuantía es ínfima, las decisiones son inapelables; d) economía pecuniaria: las costas y gastos de justicia son normalmente menores en los asuntos modestos y, en numerosas circunstancias, los impuestos de justicia se suprimen como una colaboración del Estado a una más económica solución de estos conflictos; e) Tribunales especiales: frecuentemente cierto tipo de conflictos, en particular aquellos de escaso monto pero no considerable repercusión social, se dirimen ante tribunales ajenos a la jurisdicción ordinaria, procurando no sólo la especialización, sino también la economía o aun la gratuidad de la justicia, especialmente, arrendamientos, conflictos del trabajo, etc. (p. 190).

Por lo tanto, el principio de economía procesal se define como la aplicación de un criterio utilitario en la realización empírica del proceso con el menor desgaste posible de la actividad jurisdiccional.

\section{Gratuidad de la Justicia}

El acceso a la justicia cada vez ha sido más aceptado como un derecho social básico en las sociedades modernas es el derecho humano primario en un sistema legal que pretenda garantizar los derechos tanto individuales como colectivos.

Acceder a la justicia se torna cada vez más difícil para quienes carecen de recursos económicos para lograr una resolución judicial pronta y ajustada a derecho. La población continúa percibiendo al sistema de administración de justicia como ineficaz y tendiente a la corrupción. Los esfuerzos desarrollados por las autoridades judiciales para crear nuevas instituciones como los Módulos Básicos de Justicia, con el objeto de modernizar y superar los atrasos existentes en materia normativa se ven limitados y obstaculizados por la carencia de recursos y por los continuos intentos del Poder Ejecutivo por partidarizar a su favor las diversas instancias del poder judicial.

Los litigantes no tienen ya que soportar una parte considerable de los antiguos gastos de justicia; esas costas están ahora a cargo del Estado. Se han suprimido, en particular, los timbres de los documentos, el registro de estos y de los fallos, los derechos de archivo (menos en el tribunal de comercio), y los gastos postales de los secretariados- archivos. Pero, a despecho de esta reforma, el recurrir a la justicia no es enteramente gratuito, sino que continúa siendo costoso. (Enciclopedia Jurídica, 2018).

En efecto, el litigante tiene que pagar, como antes, los costos de los actos y de las notificaciones realizados por auxiliares de la justicia (escribanos y procuradores de justicia), los honorarios de los abogados, los gastos pendientes ante el Consejo de Estado y la Corte de Casación, más los costos de investigación y tasación periciales. Puede ser parcial o totalmente descargado de tales costos por ayuda judicial, gastos y tasas. (Enciclopedia Jurídica, 2018). 
La investigación se desarrolló con una metodología de tipo descriptivo-propositivo, ya que se actuó sobre la realidad concreta para mejorarla y/o solucionarla. Además, se utilizó un enfoque mixto, cuali-cuantitativa por tratarse de una investigación de carácter social en el que interviene la subjetividad del investigador.

El diseño usado fue documental de campo, el primero porque se requirió esbozar información desde las fuentes primarias, y el segundo, porque se obtuvo resultados directamente desde el lugar de estudio.

Los métodos utilizados fueron deductivo-inductivo; analítico-sintético, histórico-lógico. La técnica e instrumento usado para la recolección de datos fue la encuesta, aplicada a los profesionales del Derecho inscritos en el Foro de abogados de la provincia de Pichincha.

Por otro lado, la población y muestra para el estudio, estuvo conformado por 17946 abogados inscritos en el Foro de abogados de la provincia de Pichincha, sin embargo, solo se utilizó de muestra 99 abogados.

RESULTADOS

Interpretación de los resultados de las encuestas efectuadas a los profesionales inscritos en el Foro de Abogados de la provincia de Pichincha.

\section{El Arbitraje, Mediación y otras formas alternativas de resolución de conflictos}

En la Tabla 1 se refleja que el 94\% de los encuestados. No conocen que el Arbitraje, Mediación y otras formas alternativas de resolución de conflictos se encuentran garantizados por la Constitución de la República del Ecuador, mientras que un 6\% manifiesta lo contrario.

Tabla 1. El Arbitraje, Mediación y otras formas alternativas de resolución de conflictos, se encuentran garantizados por la constitución de la República del Ecuador.

\begin{tabular}{ccc}
\hline ALTERNATIVAS & FRECUENCIA & PORCENTAJE \\
\hline Si & 7 & 6 \\
No & 92 & 94 \\
Total & $\mathbf{9 9}$ & $\mathbf{1 0 0}$ \\
\hline
\end{tabular}

Por lo que se evidenció un vacío legal y procesal, pues, aunque se garantiza el Arbitraje, Mediación y otras formas alternativas de resolución de por la Constitución de la República del Ecuador, en la Constitución de la República del Ecuador (2008), No existe un adecuado procedimiento para beneficiarse y ejercer esta garantía constitucional, siendo necesario buscar una solución a al vacío legal y procesal existente. 


\section{La Ley de Arbitraje y Mediación determina los casos o materias}

En esta dimensión se constató que el 95\% de los encuestados Sí consideran que la Ley de Arbitraje y Mediación determina los casos o materias dónde procede el Arbitraje, Mediación y otras formas alternativas de resolución de conflictos, mientras que el $5 \%$ manifiesta lo contrario. (Tabla 2).

Tabla 2. La Ley de Arbitraje y Mediación determina los casos o materias dónde procede el Arbitraje, Mediación y otras formas alternativas de resolución de conflictos.

\begin{tabular}{ccc}
\hline ALTERNATIVAS & FRECUENCIA & PORCENTAJE \\
\hline Si & 94 & 95 \\
No & 5 & 5 \\
Total & $\mathbf{9 9}$ & $\mathbf{1 0 0}$ \\
\hline
\end{tabular}

Se demostró que existe un respaldo a la reforma a la Ley de Arbitraje y Mediación, incorporando el divorcio por mutuo consentimiento sin hijos ni dependientes, con la finalidad de garantizar derechos constitucionales.

\section{La Ley Notarial determina el procedimiento para los casos o materias}

En la Tabla 3 se evidencia que el $98 \%$ de los encuestados Sí consideran que La Ley Notarial determina el procedimiento para los casos o materias de competencia exclusiva de los notarios, mientras que el $2 \%$ de los encuestados consideran que No es así.

Tabla 3. La Ley Notarial determina el procedimiento para los casos o materias de competencia exclusiva de los notarios.

\begin{tabular}{ccc}
\hline ALTERNATIVAS & FRECUENCIA & PORCENTAJE \\
\hline $\mathrm{Si}$ & 97 & 98 \\
No & 2 & 2 \\
Total & $\mathbf{9 9}$ & $\mathbf{1 0 0}$ \\
\hline
\end{tabular}

La totalidad de encuestados manifestaron que la Ley Notarial determina el procedimiento para los casos o materias de competencia exclusiva de los notarios.

\section{La Ley Notarial determina como atribución exclusiva de los notarios}

En la Tabla 4, se expresa que el $98 \%$ de los encuestados Sí consideran que La Ley Notarial determina como atribución exclusiva de los notarios, tramitar divorcios por mutuo consentimiento, únicamente en los casos en que los cónyuges no tengan hijos menores de edad o bajo su dependencia, mientras que el $2 \%$ de los encuestados consideran que No es así. 
Tabla 4. La Ley Notarial determina como atribución exclusiva de los notarios, tramitar divorcios por mutuo consentimiento, únicamente en los casos en que los cónyuges no tengan hijos menores de edad o bajo su dependencia.

\begin{tabular}{ccc}
\hline ALTERNATIVAS & FRECUENCIA & PORCENTAJE \\
\hline $\mathrm{Si}$ & 97 & 98 \\
No & 2 & 2 \\
Total & $\mathbf{9 9}$ & $\mathbf{1 0 0}$ \\
\hline
\end{tabular}

Se demostró que casi la totalidad de encuestados manifestaron que La Ley Notarial determina como atribución exclusiva de los notarios, tramitar divorcios por mutuo consentimiento.

\section{La normativa que determina como atribución exclusiva de los notarios, tramitar divorcios por mutuo consentimiento}

En la Tabla 5 se muestran los resultados arrojados en donde el 98\% de los encuestados destacó que Sí consideran que la atribución exclusiva de los notarios, tramitar divorcios por mutuo consentimiento, únicamente en los casos en que los cónyuges no tengan hijos menores de edad o bajo su dependencia, vulnera el principio de gratuidad, mientras que el $2 \%$ de los encuestados consideran que No es así.

Tabla 5. La normativa que determina como atribución exclusiva de los notarios, tramitar divorcios por mutuo consentimiento, únicamente en los casos en que los cónyuges no tengan hijos menores de edad o bajo su dependencia, vulnera el principio de gratuidadmenores de edad o bajo su dependencia.

\begin{tabular}{ccc}
\hline ALTERNATIVAS & FRECUENCIA & PORCENTAJE \\
\hline $\mathrm{Si}$ & 97 & 98 \\
No & 2 & 2 \\
Total & 99 & 100 \\
\hline
\end{tabular}

Se evidenció con los resultados expuestos que, casi la totalidad de encuestados manifestaron que la atribución exclusiva de los notarios, tramitar divorcios por mutuo consentimiento vulnera el principio de gratuidad.

\section{Los divorcios por mutuo consentimiento}

En esta dimensión que se evidencia la Tabla 6 el 76\% de los encuestados Sí consideraron que en los divorcios por mutuo consentimiento, debe realizarse también de acuerdo La Ley de Arbitraje y Mediación, mientras que el $36 \%$ de los encuestados manifestaron que Tal vez sea necesario y solo el $8 \%$ de los encuestados manifestaron que No. 
Tabla 6. Los divorcios por mutuo consentimiento, únicamente en los casos en que los cónyuges no tengan hijos menores de edad o bajo su dependencia debe realizarse también de acuerdo la Ley de Arbitraje y Mediación.

\begin{tabular}{ccc}
\hline ALTERNATIVAS & FRECUENCIA & PORCENTAJE \\
\hline Si & 75 & $76 \%$ \\
Tal vez & 17 & $16 \%$ \\
No & 8 & $8 \%$ \\
TOTAL & $\mathbf{9 9}$ & $\mathbf{1 0 0 \%}$ \\
\hline
\end{tabular}

Se determinó que los divorcios por mutuo consentimiento, deben realizarse también de acuerdo La Ley de Arbitraje y Mediación.

\section{Necesidad de elaborar un anteproyecto de Ley Reformatoria al Código Civil respecto a los divorcios por mutuo consentimiento}

En la Tabla 7, se muestra que el $99 \%$ de los encuestados consideran que se debe elaborar un anteproyecto de Ley Reformatoria al Código Civil respecto a los divorcios por mutuo consentimiento.

Tabla 7. Considera necesario elaborar un anteproyecto de Ley Reformatoria al Código Civil respecto a los divorcios por mutuo consentimiento, únicamente en los casos en que los cónyuges no tengan hijos menores de edad o bajo su dependencia para garantizar el principio de gratuidad.

\begin{tabular}{ccc}
\hline ALTERNATIVAS & FRECUENCIA & PORCENTAJE \\
\hline Si & 98 & 99 \\
No & 1 & 1 \\
Total & 99 & 100 \\
\hline
\end{tabular}

Por lo tanto, se evidenció que se debe elaborar un anteproyecto de Ley Reformatoria al Código Civil respecto a los divorcios por mutuo consentimiento

\section{Necesidad de elaborar un anteproyecto de Ley Reformatoria a la Ley de Arbitraje y Mediación}

Seguidamente en la Tabla 8 se muestra que la totalidad de los encuestados consideran que con la elaboración de un anteproyecto de Ley Reformatoria a la Ley de Arbitraje y Mediación respecto a los divorcios por mutuo consentimiento, para garantizar los principios de celeridad, economía procesal y gratuidad de la justicia. 
Tabla 8. Es necesario elaborar un anteproyecto de Ley Reformatoria a la Ley de Arbitraje y Mediación respecto a los divorcios por mutuo consentimiento, únicamente en los casos en que los cónyuges no tengan hijos menores de edad o bajo su dependencia para garantizar los principios de celeridad, economía procesal y gratuidad de la justicia.

\begin{tabular}{ccc}
\hline ALTERNATIVAS & FRECUENCIA & PORCENTAJE \\
\hline $\mathrm{Si}$ & 99 & 100 \\
No & 0 & 0 \\
Total & $\mathbf{9 9}$ & $\mathbf{1 0 0}$ \\
\hline
\end{tabular}

Los resultados de la encuesta dieron a conocer la necesidad de una reforma a la Ley de Arbitraje y Mediación respecto a los divorcios por mutuo consentimiento, para garantizar los principios de celeridad, economía procesal y gratuidad de la justicia.

\section{Propuesta Anteproyecto de Ley Reformatoria a la Ley de Arbitraje y Mediación respecto a los divorcios por mutuo consentimiento, únicamente en los casos en que los cónyuges no tengan hijos menores de edad o bajo su dependencia para garantizar los principios de celeridad, economía procesal y gratuidad de la justicia}

\section{Objetivo de la propuesta}

Elaborar un Anteproyecto de Ley Reformatoria a la Ley de Arbitraje y Mediación respecto a los divorcios por mutuo consentimiento, únicamente en los casos en que los cónyuges no tengan hijos menores de edad o bajo su dependencia para garantizar los principios de Celeridad, Economía Procesal y Gratuidad de la Justicia.

\section{Justificación de la propuesta}

A través de la Ley Reformatoria a la Ley de Arbitraje y Mediación respecto a los divorcios por mutuo consentimiento, únicamente en los casos en que los cónyuges no tengan hijos menores de edad o bajo su dependencia para garantizar los principios de celeridad, economía procesal y gratuidad de la justicia. Toda la ciudadanía se vería beneficiada con el empleo del arbitraje, la medición o cualquier otra forma alternativa de resolución de conflictos.

Si bien la Constitución de la República del Ecuador (2008), se refiere a los principios de celeridad, economía procesal y gratuidad de la justicia, no existe un marco legal adecuado que la respalde y que establezca procedimientos claros rápidos y sencillos para el trámite del divorcio por mutuo consentimiento, únicamente en los casos en que los cónyuges no tengan hijos menores de edad o bajo su dependencia. Esto produce que se vulneren múltiples derechos y principios constitucionales. Por esta razón, es necesario establecer un marco legal y un procedimiento 
rápido moderno y sencillo para el divorcio por mutuo consentimiento, únicamente en los casos en que los cónyuges no tengan hijos menores de edad o bajo su dependencia.

\section{Desarrollo de la propuesta}

Ecuador como un estado constitucional de Derechos y Justicia Social, tiene la obligación de velar por la protección de los intereses de sus habitantes de acuerdo a la Constitución de la República del Ecuador (2008). Los principios de celeridad, economía procesal y gratuidad de la justicia están garantizados y establecidos en la Constitución de la República del Ecuador (2008).

En la Ley de Arbitraje y Mediación no se ha establecido competencia para el divorcio por mutuo consentimiento, únicamente en los casos en que los cónyuges no tengan hijos menores de edad o bajo su dependencia. Como consecuencia del vacío legal existente, surgió la necesidad de presentar un proyecto de ley que incorpore en la legislación ecuatoriana un marco jurídico claro sobre el divorcio por mutuo consentimiento, únicamente en los casos en que los cónyuges no tengan hijos menores de edad o bajo su dependencia.

Entre las disposiciones que presenta esta ley se encuentran: el trámite y procedimiento del divorcio por mutuo consentimiento, únicamente en los casos en que los cónyuges no tengan hijos menores de edad o bajo su dependencia. También se establece que el ejercicio de este derecho es gratuito. Por lo tanto, con la reforma a la Ley de Arbitraje y Mediación, se fortalecen los principios de celeridad, economía procesal y gratuidad de la justicia los cuales se concibieron en la Constitución de la República del Ecuador (2008), como un elemento para que los ciudadanos pudieran acceder en con celeridad y en forma gratuita a la administración de justicia, en definitiva la expedición de la Ley Reformatoria a la Ley de Arbitraje y Mediación, se consolidad como un nuevo logro en materia de fórmulas alternativas de resolución de conflictos. 


\section{LEY REFORMATORIA A LA LEY DE ARBITRAJE Y MEDIACIÓN}

Art.1. A grégruese a continuación del artículo 10 el siguiente articulo enumerado:

Art. 10 A.- Demanda Arbitral de Divorcio, - Es la que le asiste a toda persona de presentar demanda de divorcio por mutuo consentimiento, inicamente en los casos en que los cónyuges no tengan hijos menores de edad o bajo su dependencia ante el director del centro de arbitraje correspondiente o ante el árbitro o árbitros independientes que se hubieren establecido en la demanda. Cumplirá los mismos requisitos que para la demanda Arbitral.

Art.2.- Agréguese a continuación del articulo 25 el siguiente articulo enumerado: Art. 25 A. - Duración del Arbitraje en Divercios. - Una vez practicada la audiencia de sustanciación y declarada la competencia del tribunal, b́te tendrá eltérmino máximo de diez dias para expedir el laudo.

Art.3.- Agréruese a continuación del articulo 46 el siguiente articulo enumerado:

Art. 46 A.- Solicitud đe Mediación en Divercios. - Es la que le asiste a toda persona de presentar solicitud de divorcio por mutuo consentimiento, unicamente en los casos en que los cónyures no tenzan hijos menores de edad - bajo su dependencia ante el centro de mediación correspondiente o un mediador independiente debidamente autorizado. Cumplira los mismos requisitosestablecidos para de la Solicitud de Mediación.

Art.4.- Agréruese a continuación del articulo 47 el siguiente articulo enumerado: Art. 47 A. Duración de Mediación en Divorcios. - El procedimiento de mediación concluye con la firma de un acta en la que conste el acuerdo total.

Una ver practicada la audiencia de Mediación, éste tesdrá el térnino máximo decinco dias para notificar o entregar el acta donde conste el Divorcio.

\section{DISPOSICION REFORMATORIA}

Refómese en el articulo 18 de la Ley Notarial, lo siguiente; Lego del término "atribuciones" suprimase el término "exclusivas".

\section{DISPOSICION DEROGATORIA}

Quedan asimismo derogedas. a la entrads en vigencis de la presente ley. otras disposiciones de irual o inferior jerarguis que ie opontan a to dilpeesto en lo milms

\section{DISPOSICION FINAL}

DR. JOSÉ RICARDO SERRANO SALGADO

Presidente

Documento flrmado olectrónicamence

DRA. LmiA RTVAS ORDOǨxz

Secretsria Oeseral

Figura 1. Ley Reformatoria a la Ley de Arbitraje y Mediación.

\section{CONCLUSIONES}

Si bien la Constitución de la República del Ecuador (2008) instituye los principios de Celeridad, Economía Procesaly Gratuidad de la Justicia, el legislador no se ha preocupado de Reformar la Ley de Arbitraje y Mediación para garantizar el ejercicio pleno de estos principios constitucionales. 
El Arbitraje y Mediación deben cumplir su función y ser una herramienta que, en forma ágil, rápida y sencilla, permita la solución de controversias relativas a divorcios por mutuo consentimiento de acuerdo a los principios de Celeridad, Economía Procesal y Gratuidad de la Justicia.

La aplicación de los métodos y técnicas establecidos en el presente Proyecto de Investigación, permitieron extraer los elementos necesarios para construir la propuesta de reforma a la Ley de Arbitraje y Mediación.

Mediante la Ley Reformatoria a la Ley de Arbitraje y Mediación se garantizará en los divorcios por mutuo consentimiento, únicamente en los casos en que los cónyuges no tengan hijos menores de edad o bajo su dependencia para garantizar los principios de Celeridad, Economía Procesal y Gratuidad de la Justicia.

\section{REFERENCIAS}

Asamblea Nacional Constituyente. (1998). Constitución Política de la República del Ecuador. Quito: Ediciones Gab

Asamblea Nacional del Ecuador (2005). Código Civil de Ecuador. (RO-S 46: 24 de junio de 2005)

Asamblea Nacional Constituyente. (2008). Constitución de la República del Ecuador. Montecristi-Manabí: Lexis

Asamblea Nacional de Ecuador. (2009). Código Orgánico de la Función Judicial (RO-S 544: 18 de marzo de 2009)

Asamblea Nacional del Ecuador. (2015). Código Orgánico General de Procesos. (RO-S 506: 22 de mayo de 2015)

Cazorla, J. (2000). Folleto, medios alternativos para la solución de conflictos. Ibarra-Ecuador: Puce-I

Couture, E. (1958). Fundamentos del Derecho Procesal Civil. Buenos Aires: Ediciones De Palma

Di Antonio, H. (1998). Visión jurisprudencial de la separación personal y el divorcio vincular. Santa Fe: Rubinzal-Culzoni

Enciclopedia Jurídica. (2018). Consultado en http://www.enciclopedia-juridica.com/d/ gratuidad-de-la-justicia/gratuidad-de-lajusticia.htm
Fernando Séptimo. (1812). Constitución Política de la monarquía española. Cádiz-España: Imprenta Real

Ley de Arbitraje y Mediación. (1997). Derogada por Codificación No. 14, publicada en RO- S 417: 14 de diciembre del 2006

Manual de Formación Básica de Mediadores. (2013). Breve Historia de la Mediación Orígenes Históricos. la Mediación: aspectos generales. https://www.santafe.gov.ar/index. php/web/content/download/71289/345896

Planiol, M.; y Ripert, G. (1981). Tratado elemental de derecho civil. Tomo I. Puebla: Cárdenas Editor y Distribuidor

Salcedo, G. (2012). El Arbitraje, la Justicia Alternativa. Guayaquil-Ecuador: Editorial Jurídica Miguez Mosquera

Sánchez, P. (2004). Manual de Derecho Procesal Penal. Editorial IDEMSA. $1^{\circ}$ Edición. Lima

Universidad Nacional Autónoma de México. (1989). Diccionario Jurídico Mexicano. Ed. Porrúa, S.A., México

Zurita, E. (2001). Manual de Mediación y Derechos Humanos. Quito-Ecuador: Defensoría del Pueblo 